\title{
Analyses of Dermatoglyphic Patterns in Ntamante, Boki Local Government Area (LGA) of Cross River State, Nigeria
}

\author{
Andrew Donatus Abue ${ }^{1}$, Christopher Rose ${ }^{2}$, Nappier Courage ${ }^{3}$ \\ ${ }^{1}$ Department of Anatomical Science, University of Abuja, Abuja, Nigeria \\ ${ }^{2}$ Department of Behavioural Sciences, American International Medical University, Gros Islet, Saint Lucia \\ ${ }^{3}$ Department of Pharmacology, American International Medical University, Gros Islet, Saint Lucia \\ Email: andrew.abue@uniabuja.edu.ng
}

How to cite this paper: Abue, A. D., Rose, C., \& Courage, N. (2018). Analyses of Dermatoglyphic Patterns in Ntamante, Boki Local Government Area (LGA) of Cross River State, Nigeria. Advances in Anthropology, 8, 83-90.

https://doi.org/10.4236/aa.2018.83005

Received: April 15, 2018

Accepted: July 9, 2018

Published: July 12, 2018

Copyright (c) 2018 by authors and Scientific Research Publishing Inc. This work is licensed under the Creative Commons Attribution International License (CC BY 4.0).

http://creativecommons.org/licenses/by/4.0/

\begin{abstract}
Analysis of the dermatoglyphics pattern in Ntamante Boki LGA of Cross River State, South-South, Nigeria is a research work carried out with the sole aim of analysing the dermatoglyphics pattern of the Ntamante people of Boki LGA in Cross river. Two hundred persons were randomly selected for the research comprising male and females. The collection of the finger prints was done using the ink procedure described by Cummins and Midlo analysis of data that was done using SPSS. The result obtained was thus: for females, the mean standard deviation was least in the radial loop $(1 \pm 1.6)$, followed by the Arches $(4.9 \pm 3.8)$, the Whorls $(6.4 \pm 4.4)$ and highest on the Ulnar loop (9.1 \pm 9.7). Variables measured differed significantly $(p=0.05)$ with a Chi-square (X2) value of 17.41. $\mathrm{Pr}>$ Chisq $=0.053$. For males, the mean standard deviation was highest in the Ulnar Loop pattern (12.6 \pm 9.2$)$, followed by the arch pattern $(4.7 \pm 2.8)$, then the whorls $(3.3 \pm 3)$ and then the radial loops $(0.1 \pm$ $0.4)$. This index study shows a higher frequency distribution of patterns of the Ulnar Loop, followed by the arches, then the whorls and finally the radial loop in the male samples which is different from the usual trend of Ulnar loop > Whorls $>$ Arches $>$ Radial loop obtained in other ethnic groups in Nigeria following the work of Jaja et al. among the Ijaws, Ekanem et al. amongst the Annangs, Ujaddughe et al. amongst the Esan of Edo state. Sexual dimorphism was evident in this research work with males showing a higher Ulnar loop distribution $(12.6 \pm 9.2)$, while the female percentage frequency distribution was $(9.1 \pm 9.7)$. In conclusion, this study shows the percentage frequencies of patterns among the Ntamante with the Ulnar Loop >Arch $>$ Whorls $>$ Radial loop amongst the males. Amongst the females, this was the distribution of pattern: Ulnar Loop $>$ Whorls $>$ Arches $>$ Radial Loop. This is in line with
\end{abstract}


what was obtained in different ethnic groups in Nigeria with regards to the percentage frequency distribution in the females, while amongst the males, the distribution shows the distribution pattern in Asia and Europe.

\section{Keywords}

Analyses, Dermatoglyphic Patterns, Ntamante

\section{Introduction}

Faulds (1880) used fingerprints for identification of criminals. He published an article in the scientific journal "Nature" discussing fingerprints as a means of personal identification and use of printers ink as a method of obtaining such fingerprints (Fujimoto et al., 2003). He made the first fingerprint identification of a greasy fingerprint left on the alcohol bottle. Fingerprints or dermatoglyphic patterns are now used as a means of identification and diagnosis of diseases, like Down's Syndrome (Adebisi, 2008; Adamu et al., 2013; Borrofice, 1978). Basu (1976) studied digital pattern and digital ridge count in endogamous castes in Mysore. He observed high frequency of loops, moderate whorls and low arches. In pattern types, differences between sexes are highly significant. Total ridge count differences between sexes are not significant. The frequencies of the patterns of the whorls, loops and arches are calculations for each finger of both right and left hands and of both sexes and finally totaled.

Among Mongoloid populations from East Asia, the frequency of whorls is high about 46 percent, varying from 40 per cent among Japanese to 52 per cent in Chinese than among Southeast Asians about 36 per cent. Among Tibetans and Bhutanese, the frequencies are quite high (about 55 per cent). The frequency of arches is quite low among Mongoloid populations (varying from 1 to 4 per cent). From Central Asia, the frequency of whorls is little lower than 50 per cent. The highest frequency of whorls is observed among Australian aborigines (78 per cent) and Eskimo (72 per cent) after Fleisch Hacker (1951) and Plato (1983). The distribution of the frequencies of different finger patterns (in percentage) may be generalized among major population groups as follows: Whorls: Mongoloids (47) > American Indians (43) > Europeans (36) > Africans (27); Loops: Africans (64) > Europeans (60) > American Indians (52) > Mongoloids (51); Arches: Africans (9) > American Indians (5) > Europeans (4) > Mongoloids (2) (Dankmeijer, 1962).

Igbigbi and Msamati (1999), while working on the digital patterns of the Malawians observed the following: Arches were the most dominant pattern in both sexes, followed by radial loops in males, whorls in females. There is no significant sex difference in the patterns. Females had higher TFRC than males $(P<$ 0.001). Males showed higher mean PII values than females who had higher ATD angle than males. Males had significant higher a-b ridge count than females $(P>$ 
0.001). Conclusively, they observed that the TFRC, ATD angle and a-b ridge count were significantly higher in Nigerians than in Malawians. The mean PII was also higher in Nigerians than the Malawian.

Ekanem et al. (2009) studied the Digital Dermatoglyphic Patterns of Annang Ethnic group in Akwa Ibom state of Nigeria and observed that the ulnar loops were the most predominant digital pattern in females (50.1 percent) than in males (39.6 percent), followed by whorls ( 42.9 percent) in males, then arches (31.1 percent) in females and radial loop ( 2.1 percent) in males. The sex differences between these patterns were statically significant (chi2 equal to 154.569; d.f. equal to $4 ; 0.001$ greater than $P$ ). The index of pattern intensity (P11) showed a higher value in males (15.13) than females (11.88). Sexual dimorphism was also evident with the males showing a higher value in males (15.13) than the females ridge count (TFRC) $(p<0.001)$.

\section{Ntamante}

This is located in Boki Local Government Area of Cross River State, South-South Nigeria, about five Kilometres from Boje the Local government Headquarters. Her people are mostly peasant and cash crop farmers in Cocoa, Banana, Timber, etc. There are endowed with a rich forest reserve. The community is about three Kilometres from the Calabar-Ikom expressway. One of the major occupations there is Teaching, i.e. secondary and primary school.

\section{Embryology}

The limbs buds enlarge grow in size under the inductive influence of apical ectodermal ridge. Upper limb bud is soon divided into arm, forearm and the terminal flattered part called as hand plate.

The hand plate and foot plate shows linear condensations of mesoderm, which are called as digitals rays. Under the influence of AER at the tip of each digital ray, the condensed mesoderm develops into phalanges. The thin mesoderm between the two digital rays breaks down to form the notches between the digitals rays. As these notches deepen the individual digits are separated from each other.

The digital rays of upper limb bud developed into five fingers including the thumb while the digital rays of lower limb bud develop into five toes Bonnevie (1924), Bonnevie and Zummerchanik (1929), Godfrey (1993).

During development the upper limb is abducted and comes to lie by the side of the trunk. The upper limb now has lateral and medial borders. The preaxial or cranial border becomes lateral border and caudal or postaxial border becomes medial border. The thumb and radius lie on lateral side while little finger and ulna lie on medial side. The flexors are on anterior aspect and extensors are on posterior aspect.

\section{Comparative Anatomy}

Many trends in primate evolution are best exemplified by the anthropoids: 
monkeys, apes, and humans, which constitute the suborder Anthropoidea. The other primates suborder, Prosimii, includes lemurs, lorises, and tarsiers. These prosimians are more distant relatives of humans than are monkeys and apes. The primates trends, most developed in the anthropoids, can be summarized briefly. Together they constitute an anthropoids' heritage that humans share with monkeys and apes.

\section{Materials and Method}

The aim of this study is to determine the dermatoglyphics patterns of men and women in Ntamante, Boki LGA. A Cross-sectional simple random sampling method was adopted in selecting the Subjects. A total of 200 (Two hundred) subjects were used for this study.

\subsection{Materials}

1) Inking slab

2) Questionnaires and oral interviews used

3) Carmel quick drying duplicating ink to collect the prints

4) Stamp pads for absorbing the ink

5) Cotton wool for easy spread of the endorsing ink

6) Duplicating papers (A4) for collection of the prints

7) Water and soap for washing of hands

8) Hand lens for magnifying and reading the ridges and patterns

9) Protractor for measuring the ATD angles

10) Pencil for recording and drawing

11) Pen for recording and drawing

12) Ruler for marking the outlines

13) Calculator

14) Needle with a sharp point for counting the ridges.

15) Research Assistants

\subsection{Methods}

\subsubsection{Steps in Obtaining the Prints}

The subjects were asked to clean their hands with soap and water. There were also asked to dry their hands but to leave some moisture.

1) Requisite amount of ink was rubbed on the stamp pad and was uniformly spread.

2) The left hand of the subject was placed on the stamp pad which is placed on a hard surface.

3) The left palm was examined for uniformity of the ink on the palmer surface of the hand.

4) The right hand of the subjects was placed on the sheet of paper kept over the firm board from proximal to distal end. The palm is gently pressed between inter-metacarpal grooves at the root of the fingers and on the dorsal side corresponding to the thenar and hypothenar eminence. The palm was then lifted 
from the paper in the reverse order from the distal to the proximal end. The fingers printed below the palmar print. The tip of the fingers was rolled from the radial to ulnar side to include all the patterns.

5) The same procedure was repeated for the left hand on a separate paper.

6) The print sheet was coded with research ID, age, sex.

7) The prints were then subjected to detail dermatoglyphics analysis with the help of magnifying hand lens and the ridge counting was done with help of a sharp needle. The detail was noted on the same paper with pencil and pen.

8) The ink removed from the subject hands with the aid of about $1 \%$ HCL which will neutralize the ink.

\subsubsection{Procedure for Analysis of Finger Prints}

The interpretation of prints was done according to Cummins and Midlo (1939) and by Penrose (1963) and includes identification of patterns, ridge counts, measurement of distances and angles on the palm Gupta and Gupta (2013).

Finger prints identification has the following basic principles which are biological viz:

1) The configurations and details of individual ridges are permanent and unchanging.

2) The configuration type is individually variable, but they are within limits which make systemic classification possible.

3) Individual epidermal ridges are so highly variable that their characteristics even in a small area of a finger, palm or sole, are not duplicated either in another region or in a different individual.

The prints obtained were studied qualitatively and quantitatively. Qualitative study applies descriptive method without the use of numerical data.

\section{Inclusion and Exclusion Criteria}

\subsection{Inclusion Criteria}

1) This research work includes persons whose grandparents and parents are of Ntamante paternally.

2) Age range is $18-68$ years.

3) Clear prints.

\subsection{Exclusion Criteria}

1) This includes persons whose grandparents and parents are not from Ntamante paternally.

2) Age range below 18years and above 68 years.

3) Blurred prints.

\section{Results and Discussions}

Data was analyzed using SPSS for windows version 21 (IBM Corporation WY, USA) and also descriptive Statistics was used.

Table 1 shows the Percentage Frequencies in the dermatoglyphic patterns in 
the male samples of Ntamante community. The mean standard deviation was highest in the Ulnar Loop pattern $(12.6 \pm 9.2)$, followed by the arch pattern $(4.7$ $\pm 2.8)$, then the whorls $(3.3 \pm 3)$ and then the radial loops $(0.1 \pm 0.4)$.

Table 2 shows percentage frequency distribution of females in Ntamante. The mean standard deviation was least in the radial loop $(1 \pm 1.6)$ followed by the Arch $(4.9 \pm 3.8)$, the Whorl $(6.4 \pm 4.4)$ and highest on the Ulnar loop $(9.1 \pm 9.7)$. Variables measured differed significantly $(p=0.05)$ with a Chi-square $(\mathrm{X} 2)$ value of 17.41. Pr $>$ Chisq $=0.053$.

\section{Discussion}

Jaja (2008) worked on the digital patterns of the Ijaws of south-south Nigerian observed increased frequency of Ulnar loop $>$ Whorls $>$ Arches $>$ Radial loops.

Udoaka \& Udoaka (2009) studied the digital prints of 450 samples of Ijaw ethnic group in Nigerian, 250 males and 200 females. Their results showed the highest frequency of ulnar loop (45.2\%) on all the fingers in both sexes, closely followed by the whorl patterns (32.6\%), then the Arch pattern (14.28\%), and the least was the radial loop which was $7.4 \%$.

Ujaddughe (2015) studied the dermatoglyphic patterns and sex distribution in Esan ethnic group of Edo state, Nigeria and observed that the loop pattern had the highest frequency (61.7\%) followed by whorl $(24.9 \%)$, arch $(12.8 \%)$ and double whorl (0.6\%).

Ekanem et al. (2009) studied the Digital Dermatoglyphic Patterns of Annang Ethnic group in Akwa Ibom state of Nigeria and observed that the ulnar loops were the most predominant digital pattern in females (50.1 percent) than in

Table 1. Percentage frequencies of male patterns in Ntamante Males $(n=81)$.

\begin{tabular}{cccccccccccc}
\hline & \multicolumn{9}{c}{ Left } & \multicolumn{7}{c}{ Right } \\
\hline & I & II & III & IV & V & I & II & III & IV & V & Mean \pm SD \\
\hline Ulnar Loop & 16.0 & 23.5 & 9.9 & 1.2 & 1.2 & 28.4 & 13.6 & 18.5 & 8.6 & 4.9 & $12.6 \pm 9.2$ \\
Radial Loop & 0 & 0 & 0 & 0 & 1.2 & 0 & 0 & 0 & 0 & 0 & $0.1 \pm 0.4$ \\
Whorl & 1.2 & 2.5 & 1.2 & 9.9 & 4.9 & 3.7 & 6.2 & 2.5 & 0 & 1.2 & $3.3 \pm 3$ \\
Arch & 2.5 & 6.2 & 3.7 & 3.7 & 11.1 & 7.4 & 3.7 & 3.7 & 3.7 & 1.2 & $4.7 \pm 2.8$ \\
\hline$P<0.05$ & & & & & & & & & &
\end{tabular}

Table 2. Percentage frequency in Ntamante Females $(n=119)$.

\begin{tabular}{cccccccccccc}
\hline & \multicolumn{1}{c}{ Left } & \multicolumn{7}{c}{ Right } \\
\hline & I & II & III & IV & V & I & II & III & IV & V & Mean \pm SD \\
\hline Ulnar Loop & 13.4 & 26.0 & 0.8 & 2.5 & 2.5 & 10.1 & 27.7 & 2.5 & 2.5 & 2.5 & $9.1 \pm 9.7$ \\
Radial Loop & 2.5 & 0 & 0 & 0 & 0.8 & 5 & 0 & 0 & 0 & 1.7 & $1 \pm 1.6$ \\
Whorl & 1.7 & 14.3 & 3.4 & 1.7 & 10.1 & 6.7 & 1.7 & 3.4 & 10.1 & 10.9 & $6.4 \pm 4.4$ \\
Arch & 4.2 & 0.8 & 6.7 & 1.7 & 12.6 & 2.5 & 2.5 & 9.2 & 0.8 & 7.6 & $4.9 \pm 3.8$ \\
\hline
\end{tabular}

$P>0.05, X^{2}=17.41, \operatorname{Pr}>$ Chisq $=0.053$. 
males (39.6 percent), followed by whorls ( 42.9 percent) in males, then arches (31.1 percent) in females and radial loop (2.1 percent) in males. The sex differences between these patterns were statically significant (chi2 equal to 154.569; d.f. equal to 4; 0.001 greater than $P$ ). The index of pattern intensity (P11) showed a higher value in males (15.13) than the females (11.88). Sexual dimorphism was also evident with the males showing a higher value in males (15.13) than the females ridge count (TFRC) than the females $(P<0.001)$.

The distribution of the frequencies of different finger patterns (in percentage) may be generalized among major population groups as follows: Whorls: Mongoloids (47) > American Indians (43) > Europeans (36) > Africans (27); Loops: Africans (64) > Europeans (60) > American Indians (52) > Mongoloids (51); Arches: Africans (9) > American Indians (5) > Europeans (4) > Mongoloids (2), (Dankmeijer, 1962).

This index study shows a higher frequency distribution of patterns of the Ulnar Loop, followed by the arches, then the whorls and finally the radial loop in the male samples which is different from the usual trend of Ulnar loop > Whorls $>$ Arches $>$ Radial loop obtained in other ethnic groups in Nigeria following the work of Jaja et al. among the Ijaws, Ekanem et al. amongst the Annangs, Ujaddughe et al. amongst the Esan of Edo state.

Sexual dimorphism was evident in this research work with males showing a higher Ulnar loop distribution (12.6 \pm 9.2$)$, while the female percentage frequency distribution was $(9.1 \pm 9.7)$.

\section{Conclusion}

This index study shows the percentage frequencies of patterns among the Ntamante with the Ulnar Loop $>$ Arch $>$ Whorls $>$ Radial loop amongst the males. Amongst the females, this was the distribution of pattern: Ulnar Loop > Whorls $>$ Arches $>$ Radial Loop. There was a significant sexual dimorphism. What it means in this anthropological ethnography study of the Ntamantes of Boki LGA of Cross River State, South-South Nigeria is that their dermatoglyphic variables conform with other literatures obtained from other ethnic groups in Nigeria, except for the male dermatoglyphic features. It also means that with the loop pattern having the highest frequency, it means that the $\mathrm{ABO}$ blood group is dominant in the community as other research works have linked higher Ulnar Loop frequency distribution pattern in a population with this blood group.

\section{Recommendations}

Further research should be carried out on the blood group pattern in the community.

\section{References}

Adamu, L. H., Taura, M. G., Hamman, W. O., Ojo, S. A., Dahiru, A. U., Sadeeq, A. A., \& Ibrahim, A. D. (2013). Association of Lip Print and Sex among Nigerians. Nigerian 
Journal of Basic and Clinical Science, 9, 84-88. (In Press)

Adebisi, S. S. (2008). Contemporary Tools in Forensic Investigations. International Journal of Biological Anthropology, 2, 5-7.

Bonnevie, K., \& ZurMechanik der Papilarmusterbildung, I. (1929). Die Epidermis als formative Faktor in der Entwicklung der Fingerbeeren und der Papilarmusterbildung. Arch. Entwickl. Organ., 117, 384. https://doi.org/10.1007/BF02110970

Bonnevie, K. (1924). Studies on Papillary Patterns of Human Fingers. Journal of Genetics, 2, 14-16. https://doi.org/10.1007/BF02983100

Borrofice, R. A. (1978). Down's Syndrome in Nigeria: Dermatoglyphic Analysis of 50 Cases. Nigeria Medical Journal, 8, 571-576.

Cummins, H., \& Midlo, C. (1939). Finger Prints, Palms and Sole. Annals of Human Genetics, $72-75$.

Dankmeijer, J. (1962). Some Anthropological Data on Finger Prints. American Journal of Physical Anthropology, 23, 377.

Ekanem, E. P., Eluwa, M. A., Udoaffah, G. U., Ekanem T. B., \& Akpantah, A. O. (2009). Digital Dermatoglyphic Patterns of Annang Ethnic Group in Akwa Ibom State of Nigeria. The Internet Journal of Biological Anthropology, 3, No. 1.

Fujimoto, I., Yamada, Y., Morizono, T., Umetani, Y., \& Maeno, T. (2003). Development of Artificial Finger Skin to Detect Incipient Slip for Realization of Static Friction Sensation. In Proceedings of IEEE International Conference on Multisensor Fusion and Integration for Intelligent Systems (pp. 15-20). New York, NY: Institute of Electrical and Electronics Engineers. https://doi.org/10.1109/MFI-2003.2003.1232571

Faulds, H. (1880). On the Skin Furrows of the Hand. Nature, 22, 605.

Godfrey, G. (1993). Relation of Fingerprints and Shape of Palm to Fetal Blood Pressure. BMJ, 307, 405-409.

Gupta, R. K., \& Gupta, A. K. (2013). New, Easy and Effective Method to Take Dermatoglyphic Prints. National Journal of Medical Research, 3, 45-47.

Udoaka, A. I., \& Udoaka, E. G. (2009). Digital Dermatoglyphics in Ijaw Students of University of Port Harcount, Nigeria. Continental Journal of Biomedical Sciences, 3, 1-5.

Ujaddughe, M. O. (2015). Assessment of Dermatoglyphic Patterns and Sex Distribution in Esan Ethnic Group of Edo State, Nigeria. International Journal of Basic, Applied and Innovative Research, 4, 9-14. 